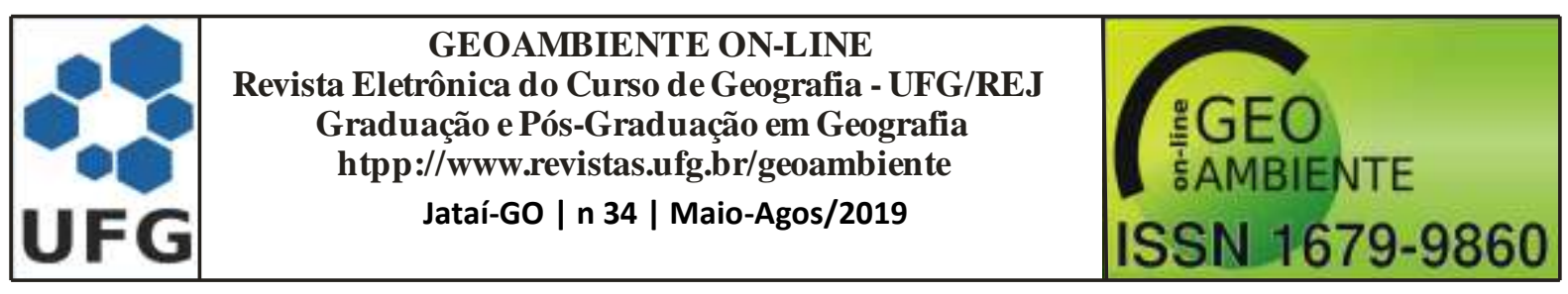

\title{
DOENÇAS (RE) EMERGENTES EM CINCO CIDADES DA REGIÃO SUL DO CARIRI CEARENSE, 2013 A 2017: PERFIL SOCIOAMBIENTAL
}

\author{
Marcus Vinicius de Macedo Fernandes ${ }^{1}$, Djailson Ricardo Malheiro² ${ }^{2}$ Christian Dennys \\ Monteiro de Oliveira $^{3}$, Pedro de Sousa Leite ${ }^{1}$
}

(1 - Faculdade de Medicina Estácio de Juazeiro do Norte, Discente em Medicina, marcusfer2012@hotmail.com; pedroed1913@hotmail.com; 2 - Faculdade de Medicina Estácio de Juazeiro do Norte, Docente, doutorando em Geografia pela Universidade Federal do Ceará - UFC, djailsonricardo@gmail.com; 3 - Universidade Federal do Ceará - UFC, Prof. Dr. do Programa de Pós-Graduação em Geografia, cdennys@gmail.com)

Resumo: As doenças infecciosas, tanto doenças emergentes como reemergentes, têm um impacto enorme na Saúde Pública, nos cuidados de saúde, na macroeconomia e na sociedade. A disponibilidade de opções para controlar e prevenir o aparecimento ou reaparecimento e expansão de agentes patogênicos requerem uma avaliação contínua. O sarampo é uma doença infectocontagiosa febril, aguda, de transmissão respiratória, sendo ainda, em algumas partes do mundo, uma das principais causas de morbimortalidade entre a população de crianças menores de 5 anos de idade. A rubéola, doença exantemática aguda, de etiologia viral, apresenta alta transmissibilidade, tem sua importância epidemiológica relacionada à Síndrome da Rubéola Congênita (SRC), podendo acarretar em inúmeras complicações causando a morte fetal e diversos defeitos congênitos. O objetivo deste artigo é analisar os casos dessas duas patologias na região de Juazeiro do Norte, Barbalha, Caririaçu, Granjeiro e Jardim - estado do Ceará, que ocorreram no período de 2013 a 2017. Os dados foram coletados por meio do site Sistema de Notificações de Agravos (SINAN/NET), utilizando ainda artigos científicos e boletins epidemiológicos fornecidos pelo Ministério da Saúde. Foram verificados 14 casos suspeitos de doenças exantemáticas (9 de sarampo e 5 de rubéola), sendo que nenhum foi devidamente comprovado. No decorrer da pesquisa pode-se verificar a relação da eficácia da

Artigo recebido para publicação em 29 de Agosto de 2018

Artigo aprovado para publicação em 16 de Agosto de 2019 


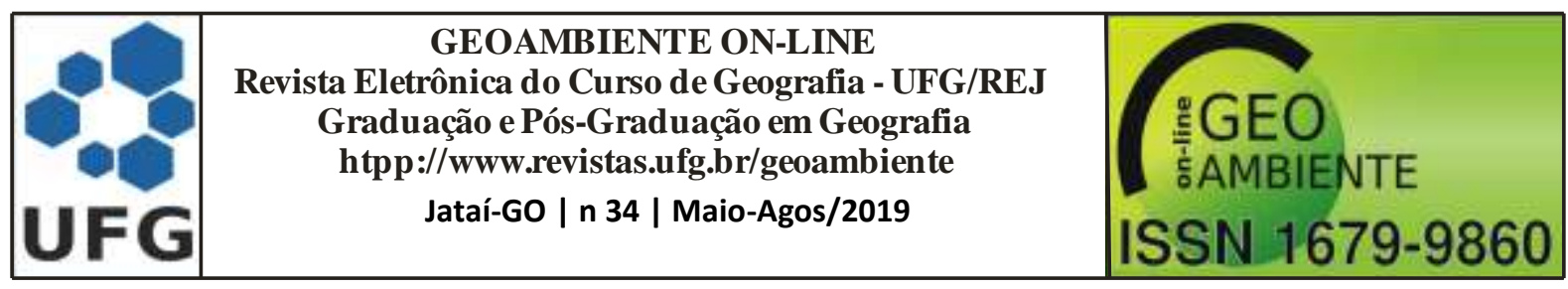

vacinação e da vigilância epidemiológica para fiscalizar e evitar o surgimento de novos surtos.

Palavras chaves: Doença, Emergentes, Rubéola e Sarampo.

\section{EMERGING (RE) DISEASES IN FIVE CITIES OF THE SOUTH REGION OF}

\section{CARIRI CEARENSE, 2013 TO 2017: ITS SOCIO-ENVIRONMENTAL PROFILE}

Abstract: Infectious diseases, both emerging and reemerging diseases, have a huge impact on public health, health care, macroeconomics, and society. The availability of options to control and prevent the onset or reappearance and spread of pathogens requires ongoing evaluation. Measles is an acute infectious contagious disease of respiratory transmission, and in some parts of the world it is one of the main causes of morbidity and mortality among the population of children under 5 years of age. Rubella, an acute exanthematic disease of viral etiology, presents high transmissibility, has an epidemiological importance related to Congenital Rubella Syndrome (CRS), and can lead to countless complications causing fetal death and several birth defects. The objective of this article is to analyze the cases of these two pathologies in the region of Juazeiro do Norte, Barbalha, Caririaçu, Granjeiro and Jardim that occurred in the period from 2013 to 2017. The data were collected through the System of Notification of Injuries (SINAN / NET), also using scientific articles and epidemiological bulletins provided by the Ministry of Health. Fourteen suspected cases of exanthematic diseases ( 9 measles and 5 rubella) were verified, none of which were duly proven. In the course of the research, it is possible to verify the relationship between vaccination efficacy and epidemiological surveillance to control and avoid the emergence of new outbreaks.

Keywords: Disease, Emerging, Rubella and Measles.

\section{NOUVELLES MALADIES (RE) DANS CINQ VILLES DE LA RÉGION SUD DE}

\section{CARIRI CEARENSE, DE 2013 À 2017: SON PROFIL SOCIO-ENVIRONNEMENTAL}

Résumé: Les maladies infectieuses, qu'elles soient émergentes ou réémergentes, ont un impact considérable sur la santé publique, les soins de santé, la macroéconomie et la société. La disponibilité d'options permettant de contrôler et de prévenir l'apparition, la réapparition et la propagation d'agents pathogènes nécessite une évaluation continue. La rougeole est une maladie contagieuse contagieuse aiguë de transmission respiratoire et constitue, dans certaines 


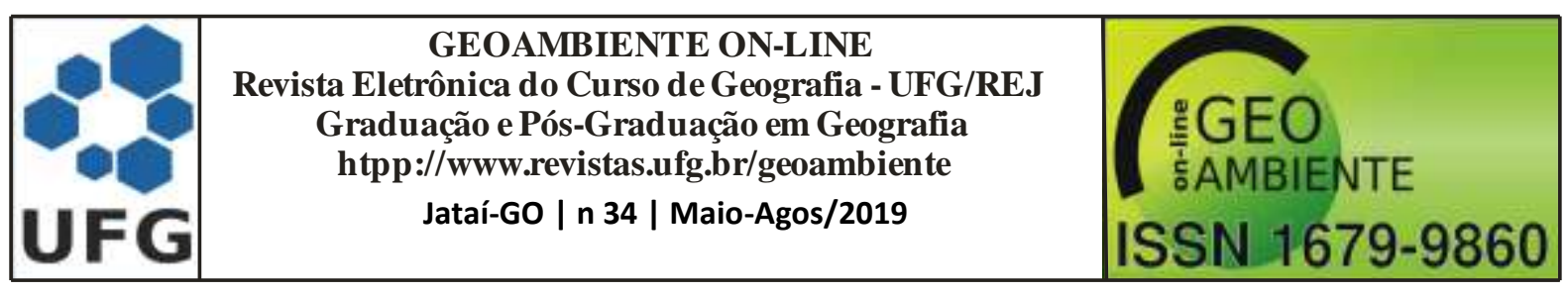

parties du monde, l'une des principales causes de morbidité et de mortalité chez les enfants de moins de 5 ans. La rubéole, une maladie exanthématique aiguë d'étiologie virale, a une transmissibilité élevée, une importance épidémiologique liée au syndrome de rubéole congénitale (SRC), qui peut entraîner d'innombrables complications entraînant la mort du fœtus et plusieurs anomalies congénitales. L'objectif de cet article est d'analyser les cas de ces deux pathologies dans la région de Juazeiro do Norte, Barbalha, Caririaçu, Granjeiro et Jardim - CE qui se sont produits de 2013 à 2017. Les données ont été collectées via le Système de notification des blessures (SINAN). / NET), utilisant également des articles scientifiques et des bulletins épidémiologiques fournis par le ministère de la Santé, et 14 cas suspectés de maladies exanthématiques ( 9 rougeole et 5 rubéole) ont été vérifiés et aucun n'a été dûment prouvé. Au cours de la recherche, il est possible de vérifier la relation entre l'efficacité de la vaccination et la surveillance épidémiologique pour contrôler et éviter l'apparition de nouveaux foyers.

Mots-clés: maladie, émergent, rubéole et rougeole.

\section{INTRODUÇÃO}

Até o final do século passado, as doenças infecciosas eram o principal problema de saúde pública, sendo responsáveis por altas taxas de mortalidade no mundo. Apesar da letalidade das doenças infecciosas, estas foram reduzidas com a implementação de políticas públicas, como a vacinação, saneamento básico, moradia adequada, entre outros serviços. No entanto, o reaparecimento de doenças patogênicas em diferentes partes do mundo demonstrou a importância de identificar novas soluções, mais rápidas e efetivas para o controle e prevenção. Estes surtos estão, eventualmente, associados ao descuido de certas regras de controle de higiene, superlotação das cidades, a presença de fatores que reduzem a capacidade de resposta dos indivíduos a patógenos e a crescente mobilidade para locais onde as doenças infecciosas não existiram anteriormente, causando consequências inesperadas (CARNEIRO, 2017).

A doença exantemática é definida como doença infecciosa sistêmica em que manifestações cutâneas acompanham o quadro clínico, gerando dificuldade diagnóstica. Nesse conjunto, podemos destacar o sarampo e a rubéola. O sarampo é caracterizado pelo exantema morbiliforme típico generalizado, acompanhado de febre e síndrome catarral. Esta 


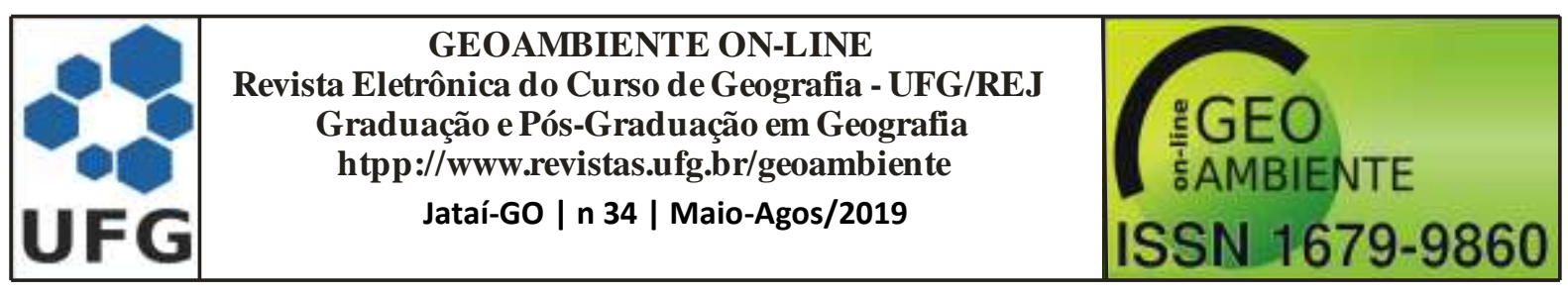

patologia possui elevada transmissibilidade por meio de secreções nasofaríngeas. A doença foi até os anos de 1980 a terceira causa de mortalidade infantil no mundo, estados do Brasil, e ainda se constitui em grave problema de saúde pública em países mais pobres (BRASIL, 2017).

O sarampo é de ampla distribuição mundial, com sua incidência, evolução clínica e letalidade aparentemente influenciada pelas condições socioeconômicas, além do estado nutricional e imunitário do doente e as condições de aglomeração e promiscuidade que podem estar presentes em habitações com superlotação. As vacinas contra o sarampo, disponibilizadas nos serviços públicos de saúde, reduzem os riscos da circulação e transmissão do vírus e, consequentemente, a morbimortalidade na população. Devido ao atual uso de uma eficiente vacina, com cobertura vacinal de $95 \%$ da população infantil, houve redução significativa de casos no Brasil e em outros países, caminhando para sua erradicação global nos próximos anos (VERONESI, 2015). Os casos ainda prevalentes são esporádicos, além de surtos localizados, provavelmente de vírus trazidos por viajantes. Recentemente, foi relatado o ressurgimento do sarampo em São Paulo como um caso importado, em 2011 (OLIVEIRA, 2012).

No Brasil, há uma ocorrência de sarampo em curso, associada principalmente a um surto que está ocorrendo na Venezuela no município de Caroni do estado de Bolívar que faz fronteira com Roraima, onde foram notificados 414 casos e 2095 no estado do Amazonas. Destes, 200 casos foram confirmados (02 óbitos) e 179 em investigação no estado de Roraima, e no estado da Amazonas 265 foram confirmados e 1.693 casos permanecem em investigação (BRASIL, 2018).

O tratamento do sarampo é essencialmente a base de sintomáticos - medicamentos que auxiliam no alívio de alguns sintomas da doença - com destaque para hidratação e alimentação adequada do doente, diminuir a hipertermia e amenizando a tosse. O tratamento profilático com antibiótico é contraindicado (VERONESI, 2015).

A rubéola é uma doença exantemática comum da infância, geralmente benigna, cujo grande impacto na saúde da população é o acometimento de gestantes, com consequente infecção do feto, causando a síndrome da rubéola congênita (SRC). O quadro clínico mais característico da rubéola adquirida é composto por febre, exantema e linfadenopatia - a febre, quando presente, frequentemente é baixa. A infecção materna na gravidez pode resultar na 


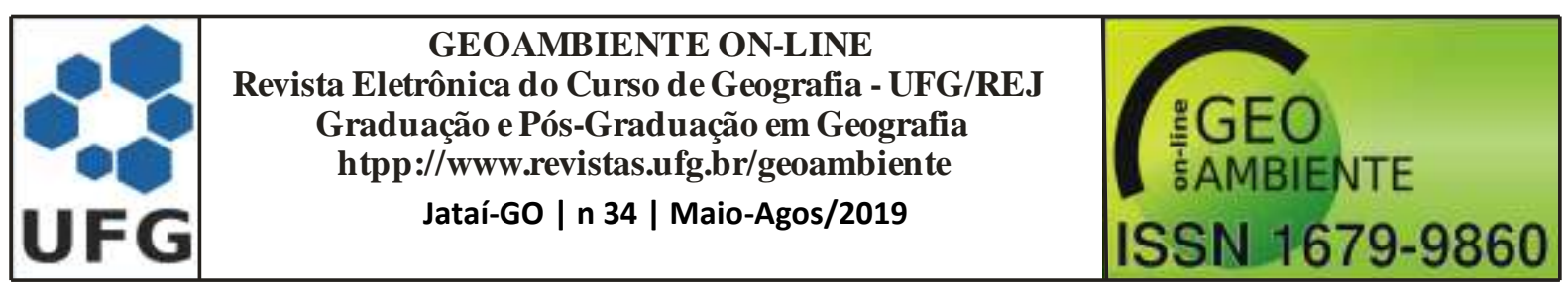

reabsorção do embrião, em abortamento espontâneo, no nascimento de um natimorto e na infecção da placenta e do feto levando à SRC (BORBA; VIDAL; MOREIRA, 2015).

Uma doença emergente é aquela que apareceu pela primeira vez, ou que pode ter existido, mas está a amplificar a incidência ou a faixa geográfica, exigindo, assim uma intervenção inovadora. Doença Reemergente resulta de uma mudança no comportamento epidemiológico de uma doença já conhecida, que tinha sido controlada, mas que volta a causar ameaça à saúde humana, sendo que para estas doenças já existem procedimentos e ações predeterminadas (CARNEIRO, 2017).

A Região das Américas foi a primeira declarada por um Comitê Internacional de Peritos (CIE) e pela Organização Pan-Americana de Saúde a ser livre do vírus da rubéola em 2015 e do sarampo em 2016. Enquanto os vírus do sarampo e da rubéola circularem em outros continentes e o fluxo de viajantes internacionais para as Américas só aumentar, espera-se que haja casos em viajantes não vacinados (CABRAL, 2017).

A análise de dados dos Laboratórios Centrais de Saúde Pública - LACEN e Vigilâncias Epidemiológicas tem demonstrado uma grande quantidade de exames sorológicos falsos positivos na pesquisa para IgM de rubéola, fato que tem gerado dificuldades no manejo clínico das gestantes e acúmulo de casos suspeitos de rubéola que não correspondem à definição de caso da doença. Além disso, devido ao vírus da rubéola estar praticamente erradicado, o Ministério da Saúde recomendou que não fosse realizado o exame sorológico com pesquisa de IgM para rubéola na rotina pré-natal para gestantes, caso a mulher esteja assintomática. A alternativa seria fazer sorologia para titulação de IgG (BRASIL, 2018).

Não havendo tratamento específico para a rubéola, se faz a prescrição de analgésicos e antitérmicos para amenizar as manifestações clínicas e dar conforto aos pacientes. Dessa maneira, a principal medida para prevenir a introdução e disseminação do vírus do sarampo e da rubéola é a vacinação da população susceptível, juntamente com um sistema de vigilância de alta qualidade e sensível o suficiente, que detecte os casos suspeitos de sarampo ou rubéola o mais precocemente possível. A vacina Tríplice Viral que protege contra sarampo, rubéola e caxumba, sendo disponível para população a partir de 12 meses de vida até 49 anos de idade. Já a Tetraviral abrange também varicela, além das doenças supracitadas, sendo disponibilizada a partir dos 15 meses de vida até 4 anos, 11 meses e 29 dias (VERANESI, 2015). 


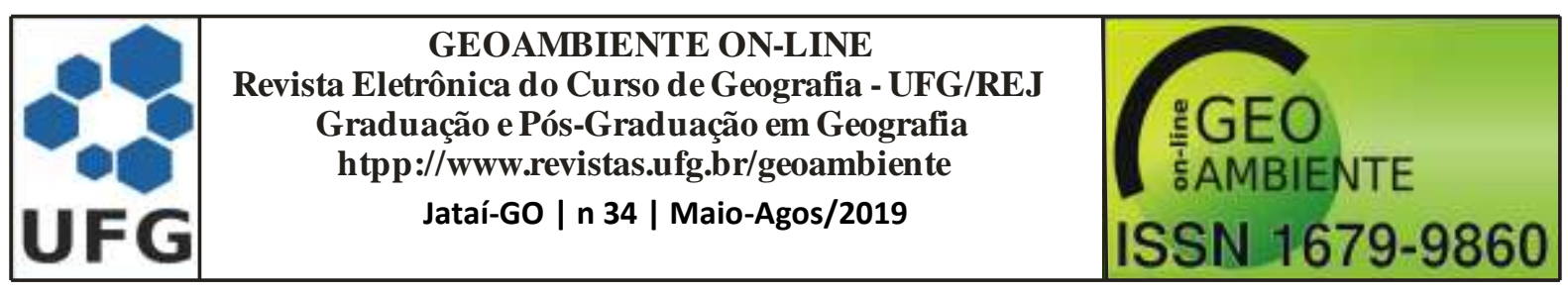

O presente trabalho tem como objetivo destacar e discutir o perfil socioambiental das doenças reemergentes, analisando as notificações dos casos de doenças exantemáticas sarampo e rubéola - no Brasil, com foco nas cidades de Juazeiro do Norte, Granjeiro, Barbalha, Caririaçu e Jardim - detalhadas na Figura 1 que demonstra o mapa da região do cariri cearense - Brasil -, destaque dos cinco municípios contemplados na pesquisa, no Sul do Ceará.

FIGURA 1. MAPA DA REGIÃO DO CARIRI CEARENSE - BRASIL, destaque dos cinco municípios

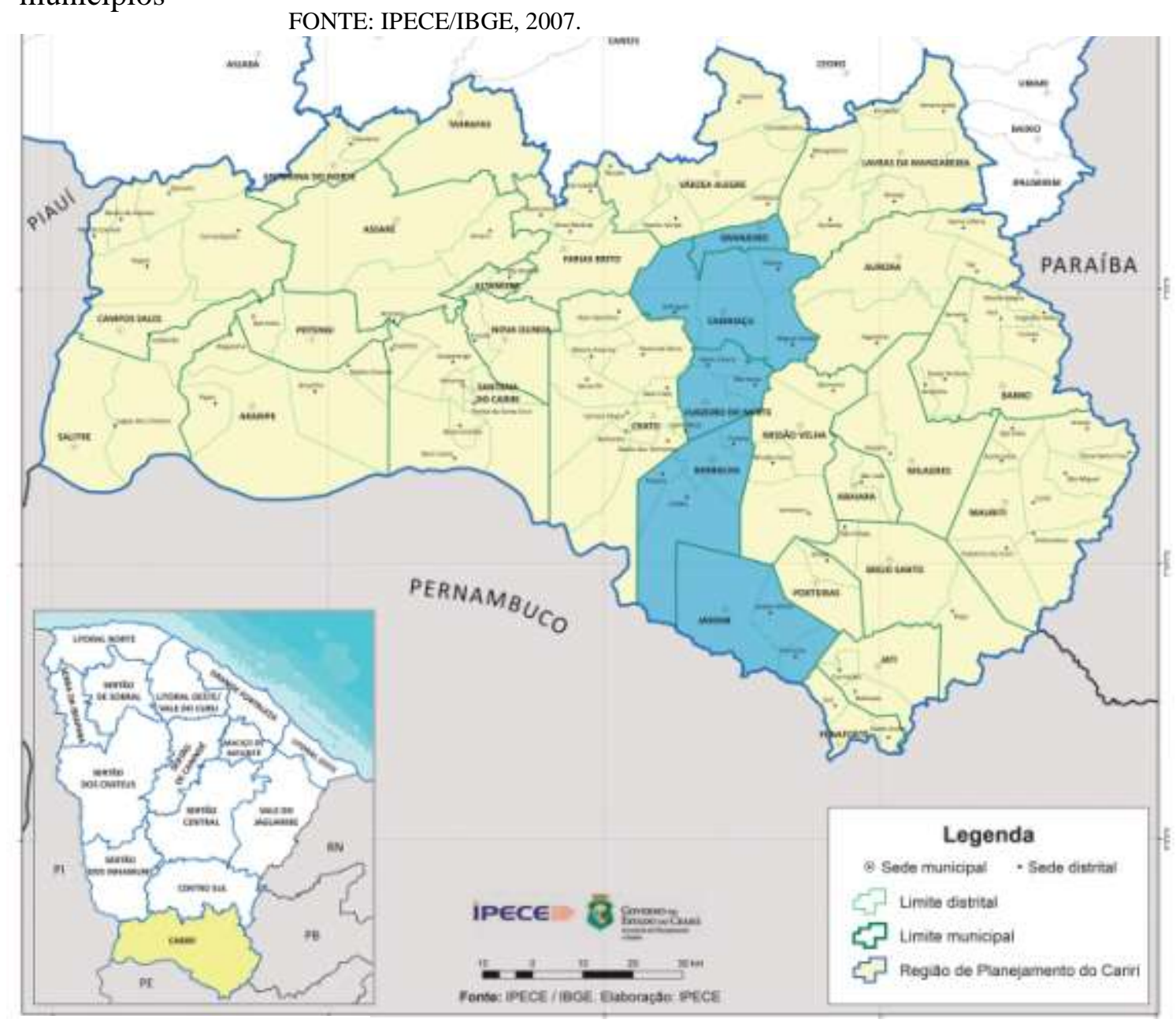

contemplados na pesquisa.

A temática para a pesquisa foi pensada devido ao contexto brasileiro atual, com os recentes alertas da Organização Mundial de Saúde (OMS) e da Sociedade Brasileira de Pediatria (SBP) a respeito dos avanços destas doenças reemergentes na região Norte do Brasil. A área de estudo escolhida, além de contemplar a segunda maior área de aglomeração 


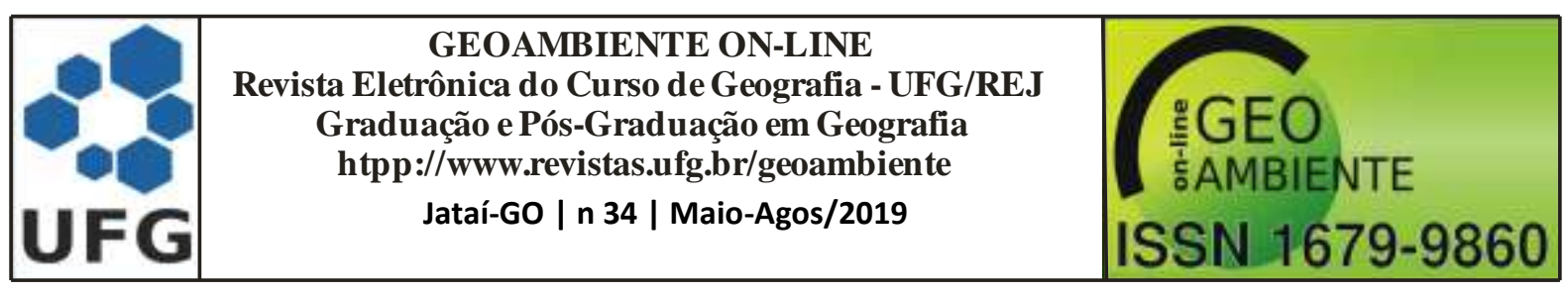

urbana do Ceará, está relacionada às semelhanças sociais, ambientais, econômicas e culturais entre os municípios escolhidos, compartilhando linhas de saúde e vigilância sanitária.

O recorte territorial preferido por este trabalho passou, nas devidas proporções, por um processo semelhante de formação urbano-regional sendo possível destacar a estruturação das atividades econômicas e organização da vida social, política e cultural em torno da região metropolitana do Cariri. Nesse contexto, também pode-se relacionar características físicoclimáticas - a exemplo das fontes perenes de água ao longo de toda a extensão da encosta da chapada do Araripe que influenciam na umidade e na pluviosidade. A vegetação também pode ser alterada dependendo do local de caatinga para cerrado ou floresta tropical.

Fortalecendo a pesquisa a partir dos aspectos geográficos como proximidades territoriais, fronteiras entre as cidades, condições socioambientais semelhantes, riscos de proliferações das doenças de maneira igualitárias e proporcionais à população de cada cidade, direcionamento das campanhas para melhor atender os cinco municípios em mesmo período e por fim a assistência em saúde muitas vezes é redirecionada entre essas localidades, para que a comunidade da região seja atendida pragmaticamente dentro do território apresentando.

\section{METODOLOGIA}

Esse artigo se trata de um estudo descritivo, exploratório e documental com análise quantitativa dos dados. Foram analisados os casos notificados de doenças exantemáticas (rubéola ou sarampo) nos municípios de Juazeiro do Norte, Barbalha, Granjeiro, Jardim e Caririaçu durante o período de 2013 a 2017.

Os dados foram coletados no site do Sistema de Notificação de Agravos (SINAN NET) e na Secretaria de Saúde de Juazeiro do Norte. Para ser verificados foram escolhidos o número de casos notificados para cada doença, o número total, a vacinação, a evolução e a classificação final de acordo com a resolução da notificação. Além das fontes já citadas, foram consultados artigos científicos, boletins epidemiológicos e notas técnicas fornecidas pela Secretaria de Saúde.

Os dados foram analisados usando-se o programa Microsoft Office Excel e os resultados apresentados em números absolutos e percentuais, sob a forma de tabelas.

Realizou-se levantamento sobre o assunto, avaliando-se as publicações em periódicos e artigos científicos, enfocando a importância teórico/prático do assunto. A busca de artigos 


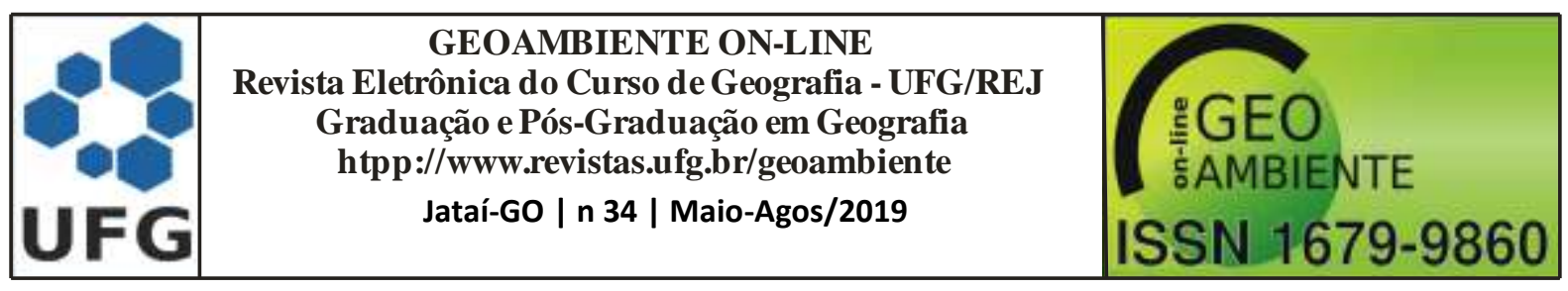

foi realizada por meio da Biblioteca Virtual em Saúde (BVS), onde foram pesquisadas as bases de dados da Literatura da América Latina e do Caribe em Ciências da Saúde (LILACS), Literatura Internacional em Ciências da Saúde (MEDLINE), Biblioteca Cochrane e Scientific Electronic Library Online (SciELO); e no United States National Library of Medicine (PubMed). Foram utilizados como palavras chaves os descritores: Doença, Emergentes, Rubeola e Sarampo.

Como critérios de inclusão, foram incluídas as publicações: (a) ocorridas entre 2010 a 2018; (b) em língua portuguesa, inglesa ou espanhola, (c) que objetivaram analisar doenças emergentes como a rubéola e ou sarampo, (d) completos.

Foram identificados 49 artigos, sendo 41 MEDLINE, 6 LILACS e 2 IBECS. O material foi inicialmente analisado pelos critérios de inclusão e exclusão. Posteriormente foi realizada a leitura prévia dos resumos dos artigos selecionados, possibilitando a aceitação ou rejeição do trabalho. Após a leitura e análise detalhada dos artigos 12 fizeram parte da amostra, por atenderem aos critérios de seleção. Foram investigadas cinco cidades localizadas na região Sul do Ceará as quais apresentamos características gerais como ano de criação, população, unidades de saúde, IDH e Clima, como pode ser observado na tabela 1.

Tabela 1. Características gerais das cidades investigadas

\begin{tabular}{lccccc}
\hline $\begin{array}{l}\text { Município } \\
\text { CEARÁ }\end{array}$ & $\begin{array}{c}\text { Ano de } \\
\text { criação }\end{array}$ & População & $\begin{array}{c}\text { Unidades de } \\
\text { saúde }\end{array}$ & IDH & Clima \\
\hline Granjeiro & 1957 & 4.629 & 7 & 0,585 & $\begin{array}{c}\text { Tropical Quente } \\
\text { Semiárido Brando }\end{array}$ \\
\hline Jardim & 1814 & 26.688 & 23 & 0,614 & $\begin{array}{c}\text { Tropical Quente } \\
\text { Semiárido e Tropical } \\
\text { Quente Semiárido Brando }\end{array}$ \\
\hline Juazeiro do Norte & 1911 & 249.939 & 129 & 0,694 & $\begin{array}{c}\text { Tropical Quente Sub- } \\
\text { úmido, Tropical Quente } \\
\text { Semiárido Brando }\end{array}$ \\
\hline Barbalha & 1846 & 55.323 & 57 & 0,683 & $\begin{array}{c}\text { Tropical Quente } \\
\text { Semiárido Brando }\end{array}$ \\
\hline Caririaçu & 1876 & 26.393 & 18 & 0,578 & $\begin{array}{c}\text { Tropical Quente } \\
\text { Semiárido, Tropical } \\
\text { Quente Semiárido Brando }\end{array}$ \\
\hline
\end{tabular}

FONTE: IPECE, 2010.

\section{RESULTADOS/DISCUSSÃO}

Nos últimos 10 anos, vários surtos de sarampo ocorreram em zonas distintas do globo, como por exemplo, na Austrália, Alemanha e Portugal. Estes casos ocorrem devido à 


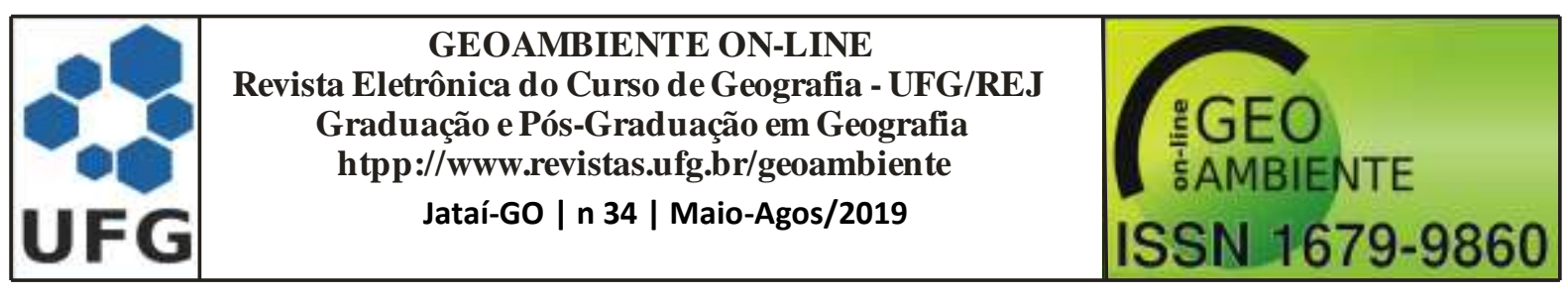

importação do vírus de outros países, pois nem todos os países têm a obrigatoriedade da vacina e os que têm nem todos os habitantes cumprem o Programa Nacional de Vacinação. Duas doses de vacina viva atenuada contra o sarampo desenvolvem uma proteção sorológica de longa duração em mais de $99 \%$ dos pacientes. Na Finlândia, por exemplo, onde um esquema de duas doses foi introduzido desde 1982 e a cobertura de vacinação chega a 98\%, (POSFAY-BARBE, 2012) o sarampo nativo foi eliminado desde 1995. Portanto, está ao alcance de se ter uma Europa sem sarampo e, subsequentemente, um mundo sem sarampo, se as recomendações forem seguidas e os médicos enfatizarem o impacto individual e na saúde pública da vacinação de todas as crianças ou do acompanhamento dos adultos não vacinados.

É importante salientar que a vacinação continua a ser o método mais bem sucedido no processo prevenção de doenças infecciosas, proporcionando a diminuição de casos de várias doenças, como também a erradicação de outras, como a poliomielite. Há vários motivos que explique a permanência de certas doenças, dificultando a sua erradicação. Entre elas, alterações clonais, processos de mutações e vírus com resistência a vacinação (BORBA; VIDAL; MOREIRA, 2015).

Neste contexto, é necessário compreender em que locais estas doenças estão e que caminhos podem ser tomados para poder prevenir situações de emergência. O Poder do Estado por meio da Agência Nacional de Vigilância Sanitária - ANVISA mantém postos de vigilância em portos e aeroportos. Estes lugares podem ser considerados estações, pelas quais passam pessoas e mercadorias que representam perigo. Essas estações estão nas fronteiras, exatamente em que dois ou mais territórios se tocam, que podem favorecer a migração de micro-organismos, contribuindo para surgimento de algumas doenças, exigindo uma fiscalização severa quanto a entrada e saída dessas patologias (DE CASTRO, 2017).

Para surgir ou ressurgir uma doença infecciosa, são necessários fatores como: alterações demográficas e ecológicas; aquecimento global; falha das vacinas; mau uso de antibióticos; resistência a inseticidas/antibióticos e, transformação e recombinação genética. Dessa maneira, um dos grandes desafios para os profissionais que atuam na atenção básica (gestores e equipe multidisciplinar) consiste justamente na dificuldade de equacionar a oferta organizada de serviços, baseada em um diagnóstico epidemiológico da saúde da população. Para o controle de um surto deve-se eliminar a fonte patogênica, corte da cadeia de transmissão e limitação da suscetibilidade. Quando a transmissão do surto é interpessoal, é 


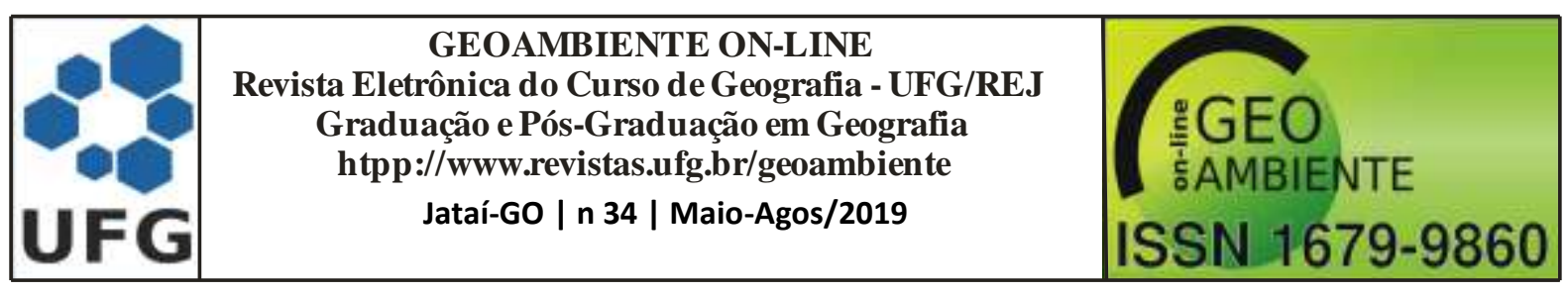

fundamental a quebra da cadeia de transmissão, bem como, a diminuição dos expostos ou potencialmente expostos através de medidas, como por exemplo, a vacinação (CARNEIRO, 2017).

O Brasil recebeu a certificação da eliminação da Rubéola em 05 de dezembro de 2015, após cinco anos sem casos registrados. No país, os últimos casos de rubéola foram detectados em 2008 e de SRC detectados em 2009. Mesmo diante deste cenário, as ações de sustentabilidade da eliminação desses vírus devem continuar, sendo a vigilância das doenças exantemáticas responsável por manter suas ações ativas de maneira a colaborar para a sensibilidade na detecção de novos casos das doenças.

Em setembro de 2016, as Américas foram consideradas livres de sarampo, mas antes haviam ocorrido surtos como em Pernambuco, entre 2013 e 2014. No Ceará, em 2013, foi confirmado o primeiro caso de sarampo após 13 anos sem registro de casos. Foram confirmados 1.052 casos de sarampo em 38 dos 184 municípios (20,7\%) do Estado, entre 2013 e 2015. Nos anos subsequentes, foram notificados no estado do Ceará 178 casos suspeitos em 2016, onde 72,0\% foram suspeitos de sarampo e 28,0\% para rubéola. Já em 2017, somente 65 casos suspeitos em todo Estado foram notificados, 61,5\% foram para sarampo e 38,5\% para rubéola. Em 2018, foram notificados nove casos de doença exantemáticas no estado do Ceará. Dentre estes, seis $(66,6 \%)$ foram suspeitos de rubéola e três $(33,4 \%)$ suspeitos de sarampo. Todos os casos foram descartados (BRASIL, 2018). Para compreender melhor os dados supracitados destaca-se a tabela 2 que demonstra os casos notificados de doenças exantemáticas das cidades que foram analisadas.

Tabela 2. Casos notificados de doenças exantemáticas

\begin{tabular}{lcccccc} 
Município Residência CEARÁ & $\mathbf{2 0 1 3}$ & $\mathbf{2 0 1 4}$ & $\mathbf{2 0 1 5}$ & $\mathbf{2 0 1 6}$ & $\mathbf{2 0 1 7}$ & Total \\
\hline Granjeiro & 0 & 0 & 0 & 0 & 1 & 1 \\
\hline Jardim & 1 & 5 & 0 & 0 & 0 & 6 \\
\hline Juazeiro do Norte & 0 & 0 & 7 & 0 & 0 & 7 \\
\hline Barbalha & 0 & 0 & 0 & 0 & 0 & 0 \\
\hline Caririaçu & 0 & 0 & 0 & 0 & 0 & 0 \\
\hline Total & 1 & 5 & 7 & 0 & 1 & 14 \\
\hline
\end{tabular}

Fonte: SINAN/NET - BRASIL, 2018.

De acordo com a tabela 2, verifica-se que não ocorreu incidência nas cidades de Barbalha e Caririaçu durante o período, sendo que em 2016, ano que ocorreu a confirmação 


\begin{tabular}{|c|c|c|}
\hline & $\begin{array}{c}\text { GEOAMBIENTE ON-LINE } \\
\text { Revista Eletrônica do Curso de Geografia - UFG/REJ } \\
\text { Graduação e Pós-Graduação em Geografia } \\
\text { htpp://www.revistas.ufg.br/geoambiente } \\
\text { Jataí-Go I n } 34 \text { | Maio-Agos/2019 }\end{array}$ & $\begin{array}{c}\text { GEO } \\
\text { JF }\end{array}$ \\
\hline
\end{tabular}

da erradicação do sarampo, também não houve notificações. Foram notificados 14 casos suspeitos, sendo, dentre estes, 9 casos suspeitos de sarampo (distribuídos da seguinte forma: 4 casos suspeitos de sarampo em Jardim e 5 casos suspeitos de sarampo em Juazeiro do Norte ) e 5 casos suspeitos de rubéola (distribuídos da seguinte forma: sendo 1 caso suspeito de rubéola em Granjeiro, 1 caso suspeito de rubéola em Jardim e 2 casos suspeitos de rubéola em Juazeiro do Norte). Curiosamente, o Ceará foi o único estado do Brasil a alcançar em 2017 a meta do Ministério da Saúde preconizada pela Organização Mundial da Saúde - possuir mais de $95 \%$ da cobertura vacinal da segunda dose de sarampo - valorizando as políticas da vigilância epidemiológicas em vigor (CARNEIRO, 2107). Nas tabelas 3 e 4, pode ser observada as cidades que apresentarão notificações dos casos de Sarampo e Rubéola e os anos que respectivamente foram localizados:

Tabela 3. Casos notificados de sarampo

\begin{tabular}{c|c|c|c}
\hline Município Residente Ceará & 2014 & 2015 & Total \\
\hline Jardim & 4 & 0 & 4 \\
\hline Juazeiro do Norte & 0 & 5 & 5 \\
\hline Total & 4 & 5 & 9 \\
\hline
\end{tabular}

Fonte: SINAN/NET - BRASIL, 2018.

Tabela 4. Casos notificados de rubéola

\begin{tabular}{c|c|c|c|c|c}
\hline Município Residências CE & 2013 & 2014 & 2015 & 2017 & Total \\
\hline Granjeiro & 0 & 0 & 0 & 1 & 1 \\
\hline Jardim & 1 & 1 & 0 & 0 & 2 \\
\hline Juazeiro do Norte & 0 & 0 & 2 & 0 & 2 \\
\hline Total & 1 & 1 & 2 & 1 & 5 \\
\hline
\end{tabular}

Fonte: SINAN/NET - BRASIL, 2018.

Pela análise das tabelas 3 e 4 pode-se avaliar a relação das patologias em relação a sua evolução, com metade dos casos terminando em cura da doença. Atualmente, devido a doença estar ausente em vários países, os sintomas do sarampo e da rubéola nem sempre são facilmente identificados pelos médicos e pais, levando à identificação errônea dos casos, como representado no gráfico pelo número significante de brancos/ignorados (BORBA; VIDAL; MOREIRA, 2015). Abaixo se identifica as tabelas 5 e 6 com dados da evolução dos casos de Sarampo e Rubéola nos municípios notificados.

A partir da análise das tabelas 5 e 6, pode-se observar que, apesar da dificuldade de se obter dados mais concretos, a ausência da vacinação poderia estar associada a incidência 


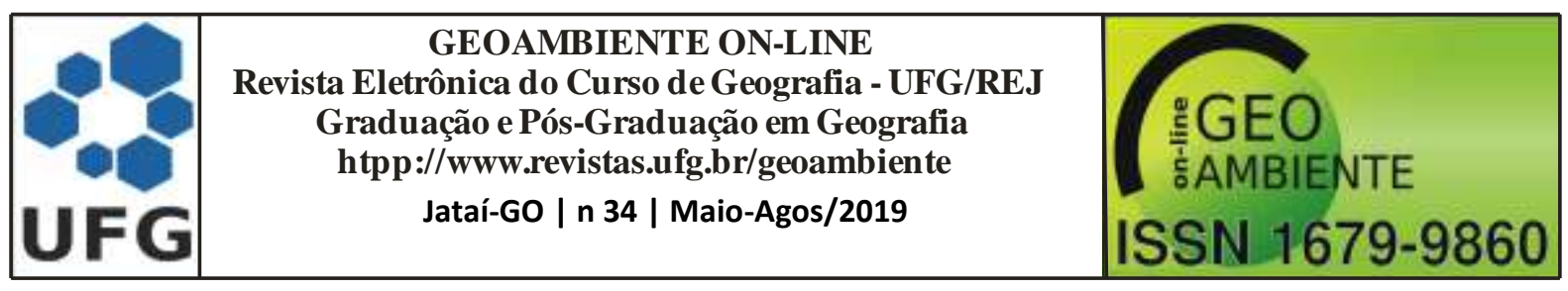

destas doenças, visto que se tem confirmação apenas de 2 casos que foram vacinados entre os 14 notificados. Para manter a supressão de sarampo, a detecção rápida dos casos é imperativa para que medidas de controle adequadas sejam implementadas. As populações não vacinadas podem representar um risco, pois o vírus continuará a ser importado, desde que permaneça endêmico a nível mundial (CARNEIRO, 2107). Na tabela 7segue os dados de vacinação de Sarampo e Rubéola nos municípios localizados no SINAN/NET, dados de 2018:

Tabela 5. EVOLUÇÃO DE CASO - SARAMPO

\begin{tabular}{c|c|c|c}
\hline Município Residências CEARÁ & Ign/Branco & Cura & Total \\
\hline Jardim & 1 & 3 & 4 \\
\hline Juazeiro do Norte & 3 & 2 & 5 \\
\hline Total & 4 & 5 & 9 \\
\hline
\end{tabular}

Fonte: SINAN/NET - BRASIL, 2018.

TABELA 6. EVOLUCÃO DE CASO - RUBÉOLA

\begin{tabular}{c|c|c|c}
\hline Município Residências CEARÁ & Ign/Branco & Cura & Total \\
\hline Granjeiro & 1 & 0 & 1 \\
\hline Jardim & 0 & 2 & 2 \\
\hline Juazeiro do Norte & 1 & 1 & 2 \\
\hline Total & 2 & 3 & 5 \\
\hline
\end{tabular}

Fonte: SINAN/NET - BRASIL, 2018.

Tabela 7. Vacinação sarampo e rubéola

\begin{tabular}{c|c|c|c}
\hline Município Residências CEARÁ & Ign/Branco & Sim & Total \\
\hline Granjeiro & 0 & 1 & 1 \\
\hline Jardim & 2 & 0 & 2 \\
\hline Juazeiro do Norte & 1 & 1 & 2 \\
\hline Total & 3 & 2 & 5 \\
\hline
\end{tabular}

Fonte: SINAN/NET Fonte: SINAN/NET - BRASIL, 2018.

De acordo com os dados coletados, não houve a confirmação de nenhum caso de sarampo ou rubéola na região de Juazeiro do Norte, Caririaçu, Barbalha, Granjeiro e Jardim, o que corrobora com a eficiência das campanhas de vacinação e medidas da vigilância epidemiológica. Entretanto, a Organização Mundial de Saúde admite que existam lacunas na imunização. Devido às alterações climáticas e à globalização, ocorrem surtos em locais novos ou onde já havia registro, mas não era problemático. $\mathrm{O}$ que torna um grande problema de saúde pública. Diante do exposto, verifica-se que a região estudada está de acordo com as metas vacinais, contudo foi verificada a reemergência de algumas doenças, o que requer 


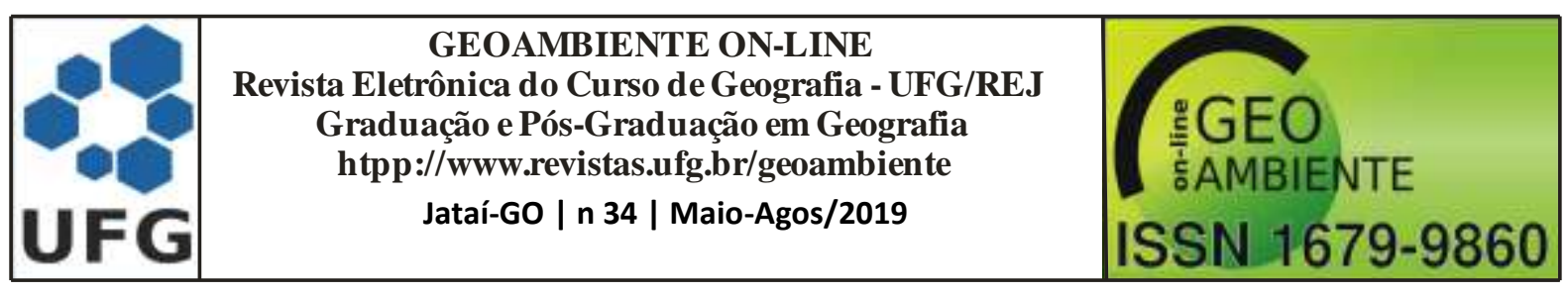

esforços dos diversos atores sociais em reorganizar políticas públicas capazes de controlar ou erradicar doenças que já estavam eliminadas (DE CASTRO, 2017).

Poliomielite, sarampo e coqueluche são doenças que estão relacionadas com surtos recentes. No qual, é importante identificar que são processos infecciosos que apresentam medidas de prevenção, em destaque a vacinação. Entretanto, recentemente aumentou a quantidade de movimentos para promoção da diminuição dessas medidas, devido efeitos colaterais. Em 2014 foi realizada uma revisão sistemática nos Estados Unidos, identificando a presença de efeitos colaterais, entretanto extremamente raros e que não sobrepõe os efeitos benéficos da profilaxia por imunização. (BORBA; VIDAL; MOREIRA, 2015).

\section{CONCLUSÃO}

- Após a análise, verifica-se uma eficiência no ofício epidemiológico ocorrido em território brasileiro, refletido nos dados apresentados nas notificações de casos de sarampo e rubéola, onde nenhum foi realmente confirmado ou evoluiu para óbito, porém ainda existem muitos países do mundo onde as doenças exantemáticas permanecem endêmicas, com erros na imunização e principalmente no controle dos casos importados.

- Diante dos dados exibidos desse artigo, pode-se observar que o sarampo e a rubéola são doenças com baixa incidência no Brasil. O surgimento de novos casos é decorrente em sua grande maioria de surtos importados, principalmente vindos da Europa e África.

- Apesar dos esforços das organizações globais de saúde, várias áreas do mundo enfrentam sérios desafios, como desmatamento, guerras, pobreza, infraestruturas inexistentes para fabricação de vacinas ou dificuldades em receber vacinas importadas. Além disso, o aumento do número de casos de doenças evitáveis por vacinação não se restringe aos países em desenvolvimento ou àqueles em guerra. Países sustentáveis, economicamente desenvolvidos e saudáveis, como Inglaterra e Austrália, também estão experimentando o ressurgimento de doenças que foram consideradas eliminadas.

- Entre 2013 e 2017 foram notificados apenas 14 casos de doenças exantemáticas envolvendo os municípios de Juazeiro do Norte, Barbalha, Caririaçu, Granjeiro e Jardim, sendo que nenhum teve realmente a sua confirmação laboratorial. 


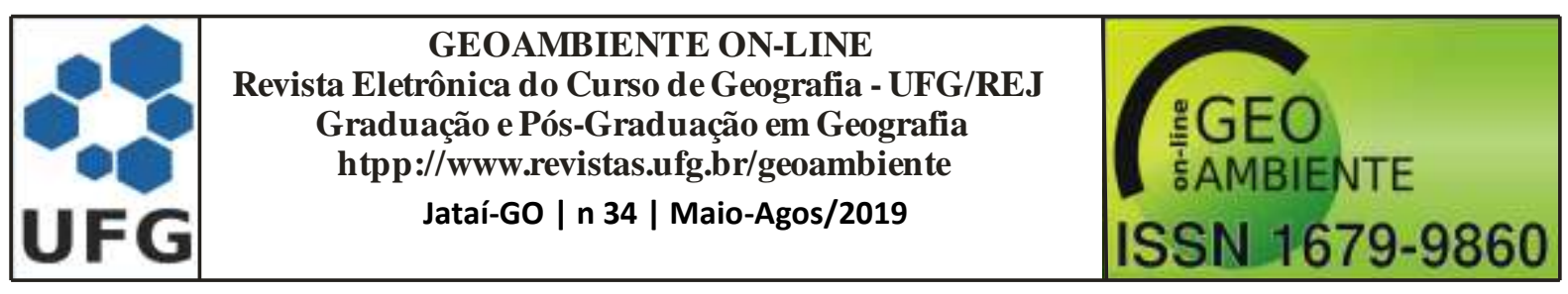

Corroborando para mostrar a eficiência das campanhas de vacinação pelo menos em relação a sarampo e rubéola no estado do Ceará. Entretanto, em virtude desta maior circulação do vírus no mundo a vigilância epidemiológica e laboratorial deve se manter em alerta, visando à detecção oportuna de casos e implementação de medidas que possibilitem interromper a transmissão e disseminação dessas doenças, principalmente em relação a casos importados e a maior fiscalização para essas patologias.

\section{REFERENCIAS}

IPECE. CEARÁ MM MAPAS. Disponível http://www2.ipece.ce.gov.br/atlas/lista/index.htm>. Acesso em: 28 nov. 2018.

BORBA, RCN; VIDAL, VM; MOREIRA, LO. THE RE-EMERGENCY AND PERSISTENCE OF VACCINE PREVENTABLE DISEASES. Anais da Academia Brasileira de Ciências, v. 87, n. 2, p. 1311-1322, 2015.

BRASIL. Ministério da Saúde. Secretaria de Políticas de Saúde. NOTA TÉCNICA SARAMPO. Brasília, DF, 2017.

- Ministério da Saúde. Secretaria de Políticas de Saúde. NOTA TÉCNICA RUBÉOLA. Brasília, DF, 2018.

CABRAL, C.M. CLINICAL-EPIDEMIOLOGICAL DESCRIPTION OF LIVE BIRTHS WITH MICROCEPHALY IN THE STATE OF SERGIPE, Brazil, 2015. Epidemiologia e Serviços de Saúde, v. 26, n. 2, p. 245-254, 2017.

CARNEIRO, RAF. DOENÇAS EMERGENTES, RESPOSTAS RÁPIDAS DE PREVENÇÃO. Tese do Mestrado Integrado em Ciências Farmacêuticas. 2017.

DA GUARDA, K.X; DA SILVA, G.T.A; DE MOURA VILLELA, E.F. PANORAMA DA COBERTURA VACINAL BRASILEIRA COM ENFOQUE NO MUNICÍPIO DE JATAÍ, Goiás entre 2011 e 2015. Revista de Epidemiologia e Controle de Infecção, v. 8, n. 1.2018. DE CASTRO, J.M; BORJA-CABRERA, G.P. AVALIAÇÃO DA COBERTURA VACINAL EM MENORES DE CINCO EM UM MUNICÍPIO DO LESTE DE MINAS GERAIS.

Ensaios e Ciência: C. Biológicas, Agrárias e da Saúde, v. 21, n. 1, p. 36-41, 2017. 


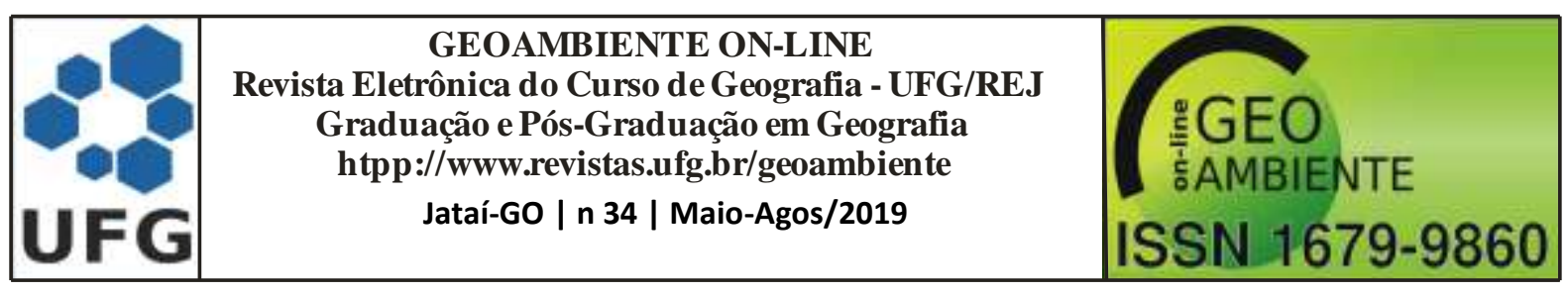

IPECE - Instituto de Pesquisa e Estratégia Econômica do Ceará. PERFIL MUNICIPAL, 2017. Disponível em: https://www.ipece.ce.gov.br/perfil-municipal-2017/>. Acesso em: 28 nov. 2018.

LEITE, R.D; BARRETO, J.L.T.M.S; SOUSA, A.Q. MEASLES REEMERGENCE IN CEARÁ, NORTHEAST BRAZIL, 15 YEARS AFTER ELIMINATION.Emerging infectious diseases, v. 21, n. 9, p. 1681, 2015.

OLIVEIRA, M.I; FIGUEIREDO, C.A; AFONSO, A.M.S; SANTOS. F.C.P;' LEMOS' X.R.M.R; YU. A.L.F; CURTI, S.P. RESURGENCE OF MEASLES VIRUS IN SÃO PAULO, BRAZIL.Revista do Instituto de Medicina Tropical de São Paulo, v. 54, n. 2, p. 113-114, 2012.

POSFAY-BARBE, K.M. INFECTIONS IN PEDIATRICS: OLD AND NEW DISEASES. Swiss Med Wkly, v. 142, n. JULY, p. 1-10, 2012.

VERONESI, R; FOCACCIA, R. TRATADO DE INFECTOLOGIA - 2 Volumes - 5 Edição, Editora Atheneu, 2015. 